\title{
Box and Gaussian plume models of the exhaust composition evolution of subsonic transport aircraft in- and out of the flight corridor
}

\author{
I. L. Karol, Y. E. Ozolin, E. V. Rozanov \\ Main Geophysical Observatory, 7 Karbyshev st., St. Petersburg, 194021, Russia
}

Received: 26 September 1995/Revised: 19 June 1996/Accepted: 3 July 1996

\begin{abstract}
A box and a Gaussian plume model including gas-phase photochemistry and with plume dispersion parameters estimated from the few available plume observations are proposed and used for evaluation of photochemical transformations of exhausts from a single subsonic transport aircraft. The effects of concentration inhomogeneities in the plume cross section on the photochemical sources and sinks in the plume are analyzed for various groups of compounds. The influence of these inhomogeneities on the rate and on the mass of ambient air entrainment into the plume are studied also by comparing the box and the Gaussian plume model simulations during the first hours of their "life". Due to the enterance of $\mathrm{HO}_{x}$ and $\mathrm{NO}_{x}$ from ambient air into the plume with rates varying from the wind shear and turbulence conditions, the rate of emitted $\mathrm{NO}_{x}$ oxidation in the plume is dependent on these and also on the background concentration levels of $\mathrm{HO}_{x}$ and $\mathrm{NO}_{x}$.
\end{abstract}

\section{Introduction}

In the extensively studied sub- and supersonic aircraft exhaust atmospheric effects the problem of exhaust plume dispersion and photochemical transformations in the plume during the first minutes and hours of the plume "life" has been relatively less investigated (see Schumann, 1994; relevant papers in Schumann and Würzel (Eds.) 1994; WMO, 1995). Some model calculations, compared with very few measurements in the exhaust plumes of transport aircraft, suggest the possibly considerable oxidation of emitted $\mathrm{NO}_{x}$ into the $\mathrm{HNO}_{3}$ and $\mathrm{HO}_{2} \mathrm{NO}_{2}$ by the $\mathrm{OH}$ and $\mathrm{HO}_{2}$ contained in the ambient air, entrained into the plume during the 10 hours or so of plume "life", when its gas and aerosol composition may be distin-

Correspondence to: Y. E. Ozolin guished from the background air (Veenstra and Beck, 1994; Karol et al., 1994). This phenomenon indicates that some significant corrections have to be made in the identifying sources and in the model estimations of large-scale and global effects of aircraft exhausts on the atmospheric composition and climate, where it has been assumed that emitted $\mathrm{NO}_{x}$ enters unchanged into the large-scale and global atmospheric systems (Ko and Douglass, 1993; Schumann, 1994; WMO, 1995). The preliminary results of model simulations reveal the obvious dependence of $\mathrm{NO}_{x}$ oxidation rate on the $\mathrm{HO}_{x}$ content in the ambient air and on the rate of its entrainment into the plume (Karol et al., 1994). These results, obtained by using the simplified box model of the plume, need to be verified by the more accurate 2-D diffusion - dispersion plume model and for different ambient air compositions, which may occur in various flight conditions: in the air transport flight corridor and outside of it, in particular.

This work presents some results of subsonic aircraft exhaust plume composition evolution in its atmospheric dispersion regime as simulated by the 2-D diffusion model of plume dispersion. These are compared to the box model results with the same dispersion parameters, obtained from actual aircraft plume crossings and measurements (see Schlager et al., 1994; Arnold et al., 1994; Schulte and Schlager, 1994; Zheng et al., 1994; Fahey et al., 1995). The time evolutions of the inputs from the photochemistry in the plume and from the ambient air entrainment to the rate of gas content change in the plume cross section are calculated and compared, for box and for diffusion plume models with various dispersion parameters, and for various $\mathrm{NO}_{x}, \mathrm{NO}_{y}$ and $\mathrm{HO}_{x}$ concentrations in the ambient air. The computed air composition evolution in the plume is compared with some observational data from the plume crossings mentioned.

\section{Plume dispersion models and their parameters}

The gas-phase photochemical processes are simulated in all the known jet, vortex and wake-dispersion regimes of 
aircraft exhaust plume evolution, which occur in 1-10; $10-100$ and more than $100 \mathrm{~s}$ of time correspondingly after leaving the engines. According to model results and observations (Miake-Lye et al., 1993; Schumann, 1994) the conservation and some increase of plume cross section dimensions and its isolation from the ambient air are assumed during the jet and vortex regimes of the plume in various calculated variants. Plume dispersion occurs in the third regime, where the horizontal plume axis is adopted as the plume axis descends by not more than 200-300 $\mathrm{m}$ from the emission level due to dynamical and radiation causes (Miake-Lye et al., 1993; Schumann, 1994). The intensive and complicated air turnover in the plume during the jet and vortex periods has lead to the adoption of the box regime for the photochemical processes there. Real deviations of gas concentrations from their homogeneity in the initial plume cross section for the dispersion regime may influence only slightly the plume photochemistry during its first few minutes.

The mass balance equation of the model is (Karol et al., 1992):

$\partial q / \partial t-A q=f(q, t)$

for the gas volume concentration $q(y, z, t)$ in the plume cross section with $t$, time; $z$, vertical; $y$, horizontal coordinate perpendicular to the plume axis; and $f(q, t)$, photochemical source - sink intensity. The air transport operator $A q$ for the box model has the form:

$A q=\left(q_{e}-q\right) d S / S d t$

where $S(t)$ is the plume cross section area; and $q_{e}$, the external gas concentration in the ambient air. For plume diffusion-dispersion where wind velocity field changes with the height according to (Karol et al., 1992; Schumann and Konopka, 1994) the Gaussian distribution parameters in the $y, z$ plane are:

$\sigma_{y}^{2}(t)=\sigma_{o y}^{2}+2 K_{y} t+s_{z}^{2} \sigma_{o y}^{2} t^{2}+2 s_{z}^{2} K_{z} t^{3} / 3$

$\sigma_{z}^{2}(t)=\sigma_{o z}^{2}+2 K_{z} t ; \quad \sigma_{y z}^{2}(t)=s_{z} t \cdot\left(\sigma_{o z}^{2}+K_{z} t\right)$

where $\sigma_{o y}, \sigma_{o z}$ are their initial values; $K_{y}$ and $K_{z}$ are the semi-empiric turbulent diffusion coefficients and $s_{z}$ is the wind shear parameter.

As discussed in Karol et al., (1994) the plume cross section ellipse area $S(t)$ is determined by its half-axes $2 \sigma_{y}$; $2 \sigma_{z}$ and it contains $91.1 \%$ of mass in the plume cross section, distributed along the 2D Gaussian distribution. In the jet and vortex regimes of the plume, during its first $150 \mathrm{~s}$, the increase of plume box dimensions from $4 \sigma_{z}=60 \mathrm{~m}, 4 \sigma_{y}=100 \mathrm{~m}$ to $4 \sigma_{z}=70 \mathrm{~m}, 4 \sigma_{y}=400 \mathrm{~m}$ is assumed, as determined by jets and vortex from the four engined Boeing-747 aircraft (Schumann, 1994; Schumann and Konopka, 1994). Then the dispersion regime begins, and its parameters are estimated from the actual plume and turbulence measurements (Schlager et al., 1994; Kärcher, 1994; Schumann et al., 1995).

These were carried out in plume crossings by research aircraft in the northeast Atlantic in October 1993. For the age of plume crossings from 300 to $5600 \mathrm{~s}$ after the emission, the coefficients $K_{z}$ and $K_{y}$ are between 0 and $0.6 \mathrm{~m}^{2} / \mathrm{s}$ and between 5 and $20 \mathrm{~m}^{2} / \mathrm{s}$ correspondingly, and $K_{z}=$ $0.3 \mathrm{~m}^{2} / \mathrm{s}$ and $K_{y}=12 \mathrm{~m}^{2} / \mathrm{s}$ may be adopted as the "best guess" values (Schumann et al., 1995). The wind shear parameter $s_{z}$ for the plume crossing periods and region are estimated to be between 0 and $(2-6) 10^{-3} \mathrm{~s}^{-1}$ from the meteorological data, such that $S_{z}$ determines the plume horizontal dispersion, that is dominant after $1-2 \mathrm{~h}$ of plume "life", but this is a less studied parameter of plume dispersion (Schumann and Konopka, 1994; Schumann et al., 1995).

Table 1 presents the compositions of the initial exhaust from the engine and of the ambient air used in the model for the midday and midnight emission moments at $10 \mathrm{~km}$ level, $50^{\circ} \mathrm{N}$ latitude and in July. The gas concentrations in the ambient air are taken for the flight corridor (FC) with enhanced $\mathrm{NO}_{x}$ and $\mathrm{H}_{2} \mathrm{O}$ and out side of it with the lower $\mathrm{NO}_{x}$ and $\mathrm{H}_{2} \mathrm{O}$ of global clean air (CA) background. It should be noted, that while the $(\mathrm{OH})$ background mixing ratio in Table 1 is twice as high in the $\mathrm{FC}$ than in the $\mathrm{CA}$, the $\left(\mathrm{HO}_{2}\right)$ mixing ratio in $\mathrm{FC}$ is about twice as low than in $\mathrm{CA}$ evidently due to about 8 times more $\left(\mathrm{NO}_{x}\right)$ in $\mathrm{FC}$ ambient air. This regulates the $\left(\mathrm{HO}_{2}\right) /(\mathrm{OH})$ ratio mostly by the known reaction $\mathrm{HO}_{2}+\mathrm{NO} \rightarrow \mathrm{OH}+\mathrm{NO}_{2}$. Variant $\mathrm{E} 1$ of emissions relates to B-747 type aircraft, while variant E2 corresponds to aircraft engines with smaller emission indices and fuel flows of B-737, B-767 type (Hoinka et al., 1993; Schumann, 1994). Basic (B) variant is an intermediate between these two. The plume dispersion parameters due to this spread of their values, are taken at their extremes: maximal $K_{z}=0.6 \mathrm{~m}^{2} / \mathrm{s} ; K_{y}=20 \mathrm{~m}^{2} / \mathrm{s}$; $S_{z}=3 \cdot 10^{-3} \mathrm{~s}^{-1}$ for the "wide" plume (WP), minimal $K_{z}=0.1 \mathrm{~m}^{2} / \mathrm{s} ; K_{y}=5 \mathrm{~m}^{2} / \mathrm{s} ; s_{z}=0$ for the "narrow"

Table 1. Initial mixing ratios of aircraft emitted gases and their background values at the $10 \mathrm{~km}$ level for the calculated variants $\left(a(b)=\mathrm{a} 10^{\mathrm{b}}\right)$

\begin{tabular}{|c|c|c|c|c|c|c|c|}
\hline \multirow[t]{3}{*}{ Gas } & \multicolumn{3}{|c|}{ Emissions (ppb) } & \multicolumn{4}{|c|}{ Background (pptv) } \\
\hline & \multicolumn{3}{|l|}{ Variants } & \multicolumn{2}{|c|}{ Flight corridor } & \multicolumn{2}{|l|}{ Clean air } \\
\hline & $\mathrm{B}$ & E1 & E2 & Day & Night & Day & Night \\
\hline $\mathrm{NO}$ & 36.0 & 72.0 & 7.2 & 160.0 & $1.1(-3)$ & 23 & $5.1(-4)$ \\
\hline $\mathrm{NO}_{2}$ & 4.0 & 8.1 & 1.1 & 120.0 & 270.0 & 19 & 36 \\
\hline $\mathrm{OH}$ & 1.4 & 0.0 & 1.2 & 0.4 & $9.2(-4)$ & 0.2 & $1.7(-3)$ \\
\hline $\mathrm{HO}_{2}$ & 0.0 & 0.0 & 0.0 & 2.9 & $8.5(-2)$ & 5.2 & $1.2(-1)$ \\
\hline $\mathrm{CO}$ & 9.0 & 17.0 & 1.0 & $3.2(4)$ & $3.2(4)$ & $3.2(4)$ & $3.2(4)$ \\
\hline $\mathrm{HNO}_{3}$ & 0.0 & 0.0 & 0.0 & $3.2(3)$ & $3.2(3)$ & 490 & 490 \\
\hline $\mathrm{H}_{2} \mathrm{O}$ & $5.5(3)$ & $1.1(4)$ & $2.3(3)$ & $1.0(8)$ & $1.0(8)$ & $1.0(7)$ & $1.0(7)$ \\
\hline
\end{tabular}


plume (NP), and the "best guess" $K_{z}=0.3 \mathrm{~m}^{2} / \mathrm{s}$, $K_{y}=12 \mathrm{~m}^{2} / \mathrm{s}, s_{z}=0$, are all considered in parallel.

The time evolution of gas contents in the plume are related to their model diurnal course in the ambient air for the relevant latitude and month, as found in Karol and Ozolin (1994). For the flight corridor (FC) ambient air the enhanced $\mathrm{NO}_{y}$ and $\mathrm{H}_{2} \mathrm{O}$ contents are used, connected with their estimates in Schumann (1994); Schumann and Konopka (1994) and Hoinka et al. (1993).

Only the gas phase photochemical reactions are considered here in the first study. In Karol and Ozolin (1994), it was shown that the heterogeneous reaction of $\mathrm{N}_{2} \mathrm{O}_{5}$ with $\mathrm{H}_{2} \mathrm{O}$ on the ambient air aerosol surface and on one type of aerosols in the plume influence only the $\mathrm{N}_{2} \mathrm{O}_{5}$ evolution in the plume. The more detailed estimation of influence of heterogeneous reactions on aerosols in the plume will be considered later.

About 85 gas phase reactions for following 33 variable compounds of the most important gas "families" are taken into account and listed in Table 2: $\mathrm{O}_{3}, \mathrm{O}, \mathrm{O}\left({ }^{1} \mathrm{D}\right), \mathrm{H}, \mathrm{OH}$, $\mathrm{HO}_{2}, \mathrm{H}_{2} \mathrm{O}_{2}, \mathrm{~N}, \mathrm{NO}, \mathrm{NO}_{2}, \mathrm{NO}_{3}, \mathrm{~N}_{2} \mathrm{O}_{5}, \mathrm{HNO}_{2}, \mathrm{HNO}_{3}$, $\mathrm{HO}_{2} \mathrm{NO}_{2}, \mathrm{Cl}, \mathrm{ClO}, \mathrm{HCl}, \mathrm{HOCl}, \mathrm{ClONO}, \mathrm{ClOO}, \mathrm{Cl}_{2}$, $\mathrm{CH}_{3}, \mathrm{CH}_{3} \mathrm{O}_{2}, \mathrm{CH}_{3} \mathrm{O}_{2} \mathrm{H}, \mathrm{CH}_{3} \mathrm{O}, \mathrm{CH}_{2} \mathrm{O}, \mathrm{HCO}, \mathrm{H}_{2}, \mathrm{~N}_{2} \mathrm{O}$, $\mathrm{H}_{2} \mathrm{O}, \mathrm{CO}, \mathrm{CH}_{4}$. Numerical realization of the box model is the same as in Karol et al. (1994). In cross section vertical and horizontal plume diameters contain 15 and 30 grid points correspondingly at each time moment.

Special attention is paid to calculations of mass balance components at every time step. Absolute and relative inputs of photochemical sources-sinks, intensities of separate compounds and of their flow through the plume boundary into the rate of gas mass change in the plume cross section are evaluated for both plume models. In the box model the numerical estimation of the boundary flow by the formula (2) is checked by its variant with analytical time differentiation of the plume cross section area $S(t)=$ $4 \pi \sigma_{z}(t) \sigma_{y}(t)$ with the expression (3) for $\sigma_{z}(t)$ and $\sigma_{y}(t)$.

For the Gaussian plume model the technique of plume cross boundary flow calculation by the usual diffusion formula leads to significant computational errors due to the rough numerical calculation of gas concentration gradient over the plume boundary, especially at the end of plume "life", when this gradient is small. Therefore, the gas flow through the Gaussian plume boundary is evaluated as the balance residue of the gas content rate in the plume

Table 2. List of gas phase photochemical reactions included in model

\begin{aligned} \hline 1. & $\mathrm{O}_{2}+h v \rightarrow \mathrm{O}+\mathrm{O} \\ 2 & . \mathrm{O}_{3}+h v \rightarrow \mathrm{O}\left({ }^{1} \mathrm{D}\right)+\mathrm{O}_{2} \\ 3 & . \mathrm{NO}_{2}+h v \rightarrow \mathrm{NO}+\mathrm{O} \\ 4 & . \mathrm{NO}_{3}+h v \rightarrow \mathrm{NO}_{2}+\mathrm{O} \\ 5 & . \mathrm{NO}_{3}+h v \rightarrow \mathrm{NO}+\mathrm{O}_{2} \\ 6 & . \mathrm{N}_{2} \mathrm{O}_{5}+h v \rightarrow \mathrm{NO}_{2}+\mathrm{NO}_{3} \\ 7 & . \mathrm{HNO}_{3}+h v \rightarrow \mathrm{NO}_{2}+\mathrm{OH} \\ 8 & \mathrm{H}_{2}+h v \rightarrow \mathrm{OH}+\mathrm{OH} \\ 9 & . \mathrm{HCl}_{2}+h v \rightarrow \mathrm{H}+\mathrm{Cl} \\ 10 & . \mathrm{ClONO}_{2}+h v \rightarrow \mathrm{Cl}+\mathrm{NO}_{3} \\ 11 & . \mathrm{HOCl}^{2} h v \rightarrow \mathrm{Cl}+\mathrm{OH}^{2} \\ 12 & . \mathrm{HO}_{2} \mathrm{NO}_{2}+h v \rightarrow \mathrm{HO}+\mathrm{NO}_{2} \\ 13 & . \mathrm{Cl}_{2}+h v \rightarrow \mathrm{Cl}+\mathrm{Cl}\end{aligned}$

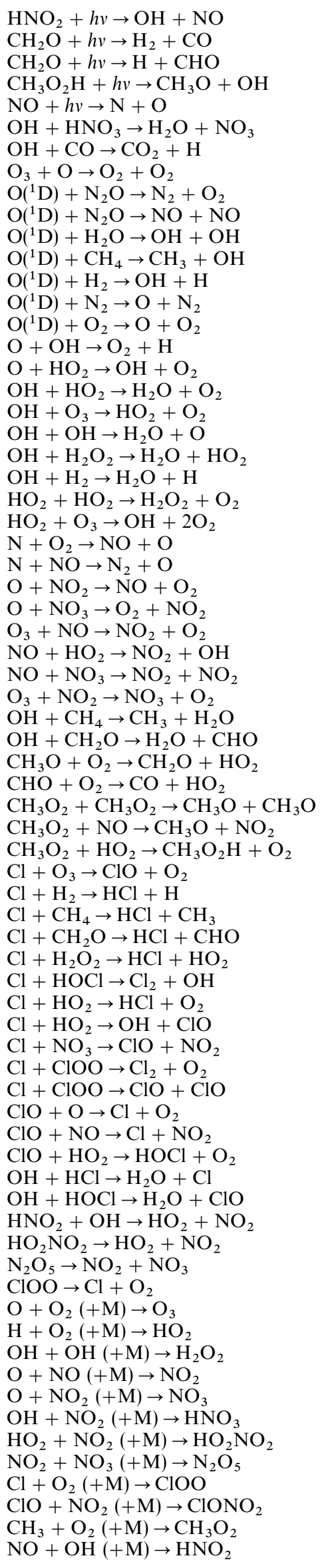


cross section. Special studies reveal that this evaluation has an error of about $10-30 \%$ and is more precise than the usual diffusion formula.

\section{Results of calculations}

The calculated time evolution of ozone, $\mathrm{NO}_{x}=\mathrm{NO}+$ $\mathrm{NO}_{2}, \mathrm{HO}_{x}, \mathrm{HNO}_{2}, \mathrm{HNO}_{3}, \mathrm{HO}_{2} \mathrm{NO}_{2}$ component mixing ratios in the box model of the plume relative to their background diurnal courses are very close to these presented in Karol and Ozolin (1994), for $10 \mathrm{~km}$ level and they are not repeated here. As in the latter paper the ozone depletion, up to a maximum of $20 \%$, occurs during the first minutes of plume life in the jet and vortex regimes with little air exchange through the plume boundary. This ozone change does not influence, in practice, the plume composition evolution in the plume dispersion regime (Karol et al., 1994; Veenstra and Beck, 1994).

Figure 1 compares the $\mathrm{NO}, \mathrm{OH}$ and $\mathrm{HNO}_{2}$ mixing ratio distributions along the plume axis horizontal cross radius in the box and in the 2D Gaussian plume models for the basic variant in the flight corridor (FC) at $25 \mathrm{~min}$ after the midday injection. Figure 1 shows that $\mathrm{NO}$ and $\mathrm{HNO}_{2}$ are spreading from the plume, but the $\mathrm{OH}$ deficit in the plume must be replenished from the outside $\mathrm{HO}_{x}$. The spatially averaged compound content over the plume horizontal radius of $400 \mathrm{~m}$ in the $2 \mathrm{D}$ plume model is evidently close to its value in the box model. The $\mathrm{HNO}_{3}$ and $\mathrm{HO}_{2} \mathrm{NO}_{2}$ distributions over the centered horizontal Gaussian plume cross section are close to their concentrations in the box model, indicating the much smaller effects of their transport through the plume boundary on evolution of their content in the plume. The same relations hold during the whole plume "life" for most of gases as may be

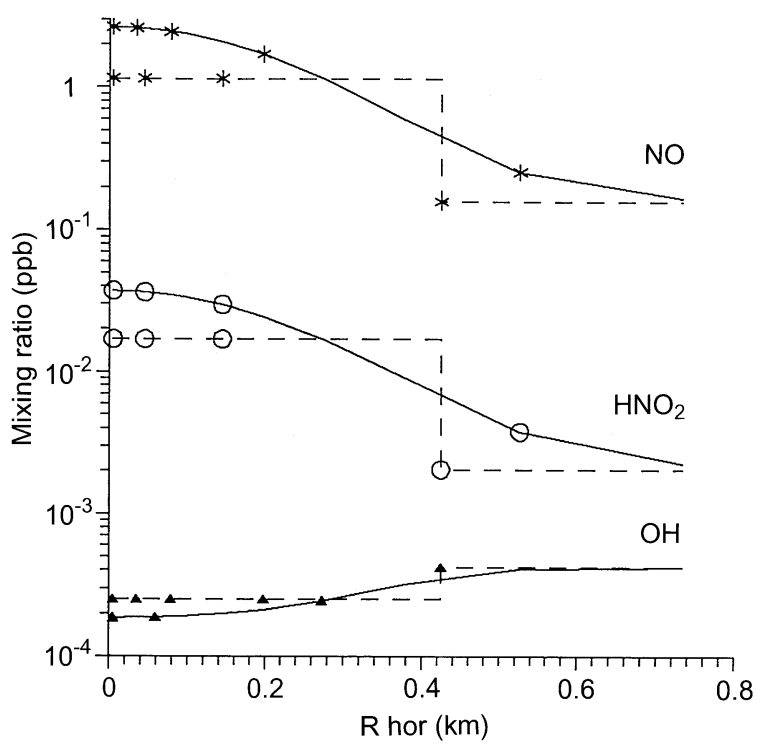

Fig. 1. $\mathrm{NO}, \mathrm{HNO}_{2}$ and $\mathrm{OH}$ mixing ratio distributions along the plume axis horizontal cross radius in the box (dashed lines) and the 2-D Gaussian (solid lines) plume models for the basic variant in the flight corridor (FC) at $25 \mathrm{~min}$ after the midday injection seen from Fig. 2, which presents the time evolution of $\mathrm{HNO}_{2}$ mixing ratios: at the Gaussian plume axis, at plume edge and integrated over the plume cross section area related to $\mathrm{HNO}_{2}$ mixing ratio in the box model for the same basic variant. These relations become close to unit (gas mixing ratios in the Gaussian plume tend to uniformity in plume cross section) at the end of plume "life" considered here. The rate of this tendency is different for various gases: for instance it is less rapid for $\mathrm{NO}_{x}$ and $\mathrm{HO}_{2}$.

Figure 3 demonstrates plume model sensitivity to atmospheric dispersion parameters and compares the calculated (NO) mixing ratio time evolution in the box plume

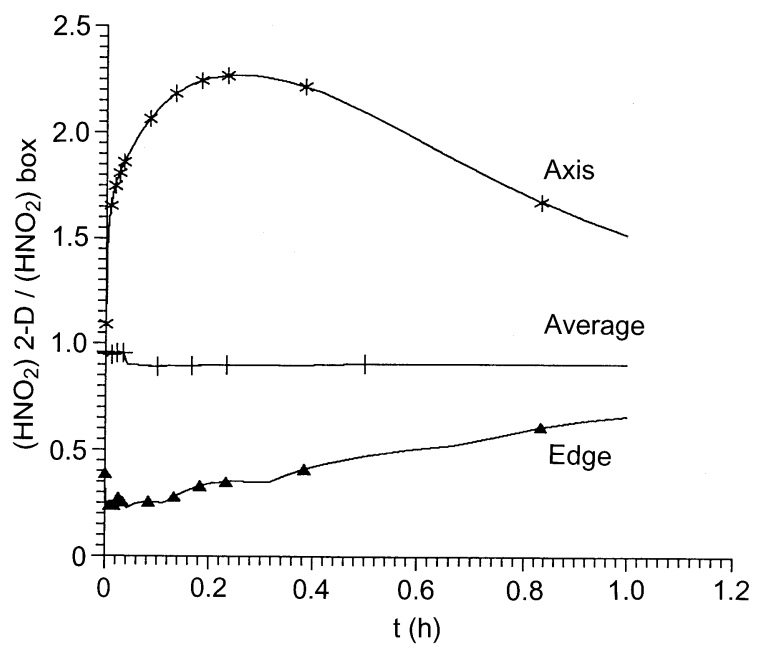

Fig. 2. Time evolution of the $\mathrm{HNO}_{2}$ mixing ratio: at the Gaussain plume axis; at this plume edge; and integrated over the plume cross section area (average) - relative to the $\mathrm{HNO}_{2}$ mixing ratio in the box model for the same basic variant

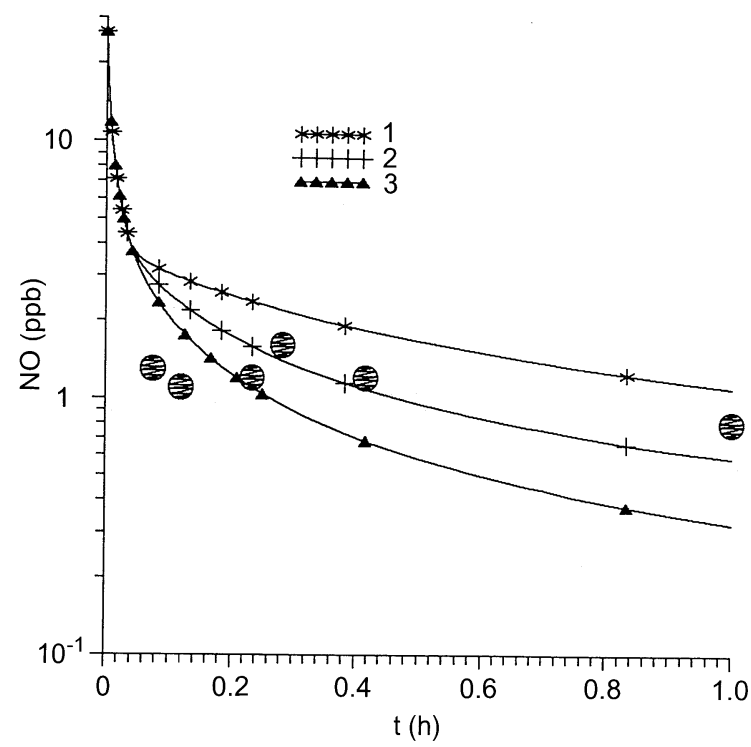

Fig. 3. Time evolution of the (NO) mixing ratio in the model box: 1 , narrow plume; 2 , basic, 3 , wide plume, and circles, measured (NO) in cross section of various exhaust plumes over the eastern Atlantic (Schlager et al., 1994) 
with measured (NO) in cross sections of various exhaust plumes by the research aircraft over the eastern Atlantic (Schlager et al., 1994). It is evident, that (NO) in the narrow plume box model is very different from the real data for plume age beyond $10 \mathrm{~min}$, but then basic box model results are close to measurements. It may be concluded from Fig. 3, that during the plume evolution (NO) mixing ratio in the box plume becomes less dependent from $\sigma_{o z}, \sigma_{o y}$ and more sensitive to atmosphere dispersion parameters $K_{y}, K_{z}$.

Figures 4, 5 and 6 compare some variants of the time evolution of $\mathrm{NO}, \mathrm{OH}, \mathrm{HNO}_{3}$ balance components in the

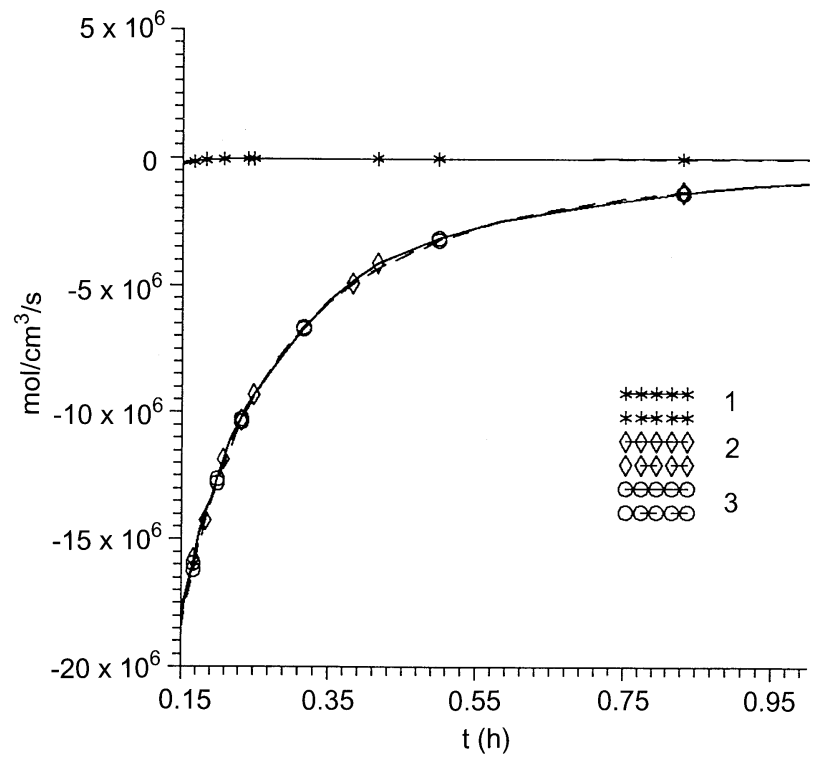

Fig. 4. Time evolution of $\mathrm{NO}_{x}$ content rate of change in cross section of box (dashed line) and Gaussian (solid line) model plumes; 1 , due to photochemical processes; 2 , due to plume trans-boundary air transport; 3, total

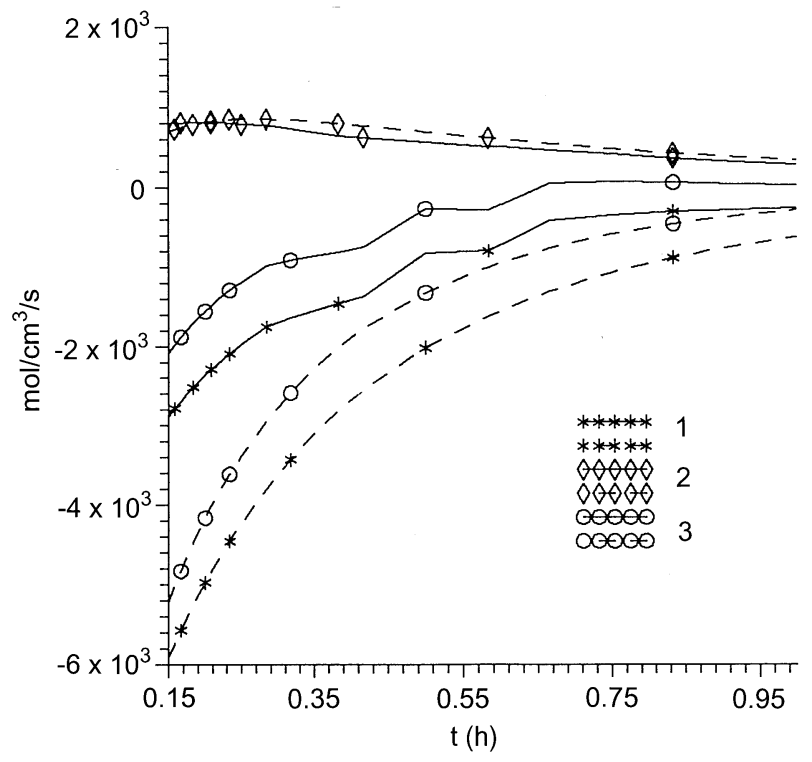

Fig. 5. Same as in Fig. 4 but for $\mathrm{OH}$ evolution cross sections of box and Gaussian plume models. In both the models the inputs of photochemical transformations and of the air exchange through plume boundary into the rate of gas cross section content change have opposite signs for most of the gases and their maxima are in the first minutes of the plume dispersion regime. These maxima and input levels are almost the same in the box and in the Gaussian model for all gases at all times. Only the photochemical consumption of the short-lived $\mathrm{HO}_{x}$ components and, therefore, their total change rates in the plume cross section are higher in the box than in the Gaussian model (see Fig. 5). The total gas content change rates in the plume cross section are much less and almost coincide in both models for all gases and for variants with the same parameters. Photochemical transformations and plume boundary air transport components of the change rates always act in opposite directions and partly compensate each other. Therefore, the differences between the plume box and Gaussian models in the photochemical transformation and in the gas transport rates through the plume boundary, being not very significant separately, produce almost the same total gas content change in the plume cross sections during the whole plume "life" period. This important conclusion is valid for all the gases considered and confirms the use of the simpler and handier box model for studying the general effects of the aircraft exhaust plume, of its dispersion and photochemistry on the ambient atmosphere. Only the plume box models are used in most of the studies of this effect (Danilin et al., 1992; Karol et al., 1994; Pleÿel et al., 1994; Veenstra and Beck, 1994 and others), and the above results give them an additional basic support.

Only the results from the box model simulations will be presented below. Figures 7-10 demonstrate the time evolution of $\mathrm{NO}, \mathrm{NO}_{x}, \mathrm{HNO}_{2}, \mathrm{HNO}_{3}, \mathrm{HO}_{2} \mathrm{NO}_{2}$ contents over their backgrounds relative to total odd nitrogen $\mathrm{NO}_{y}=\mathrm{NO}_{x}+\mathrm{NO}_{3}+\mathrm{HNO}_{2}+\mathrm{HNO}_{3}+\mathrm{HO}_{2} \mathrm{NO}_{2}+$ $2 \mathrm{~N}_{2} \mathrm{O}_{5}$ amount in the plume cross sections and their

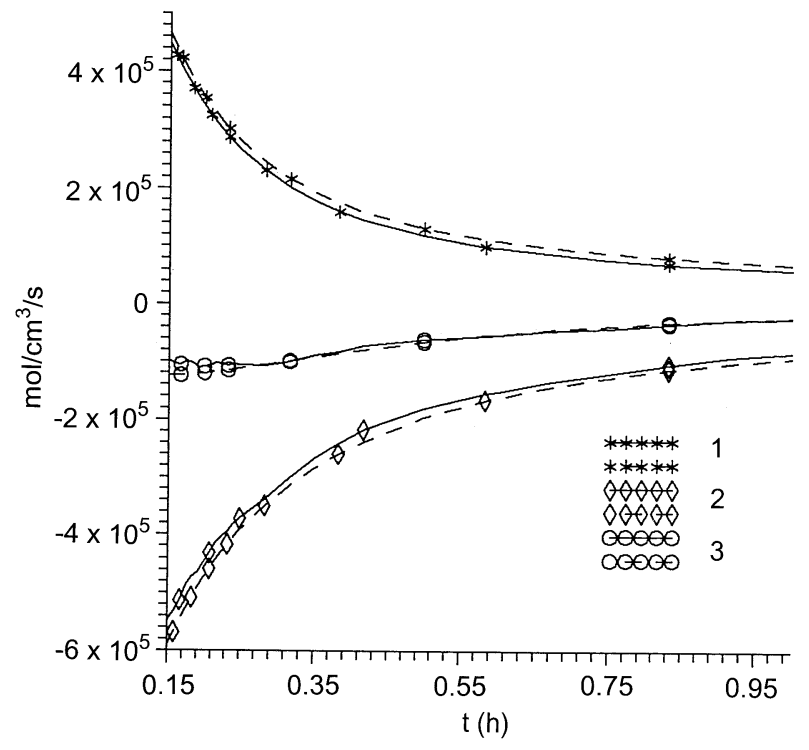

Fig. 6. Same as in Fig. 4 but for $\mathrm{HNO}_{3}$ evolution 


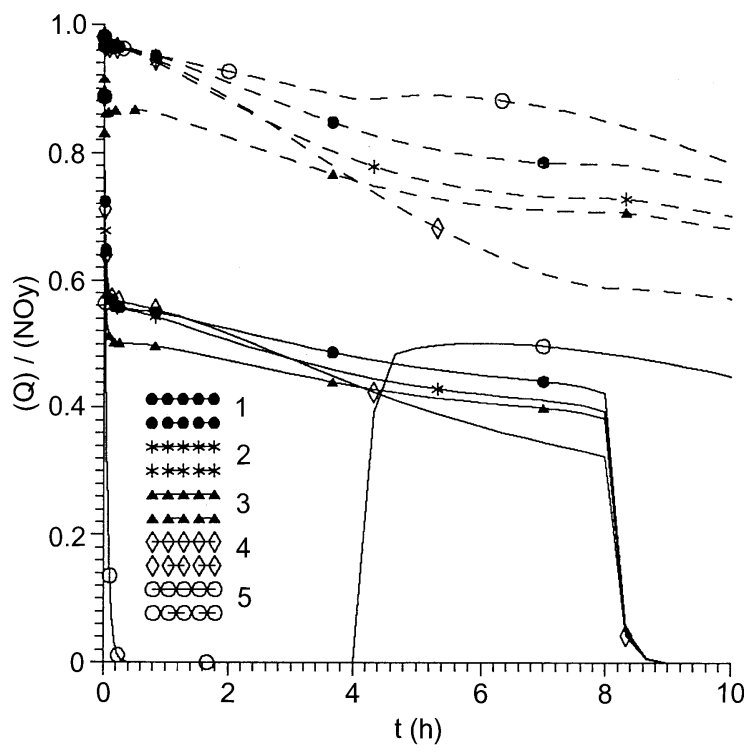

Fig. 7. Time evolution of $\mathrm{NO}$ (solid lines) and $\mathrm{NO}_{x}$ (dashed lines) relative to $\mathrm{NO}_{y}$ contents in the plume box model over their backgrounds for B midday emission in FC and for variants with: 1, basic plume; 2, wide plume; 3, basic plume with five times increased emission of $\mathrm{OH}$ : 4, basic plume in clean air; 5, midnight basic injection in the flight corridor

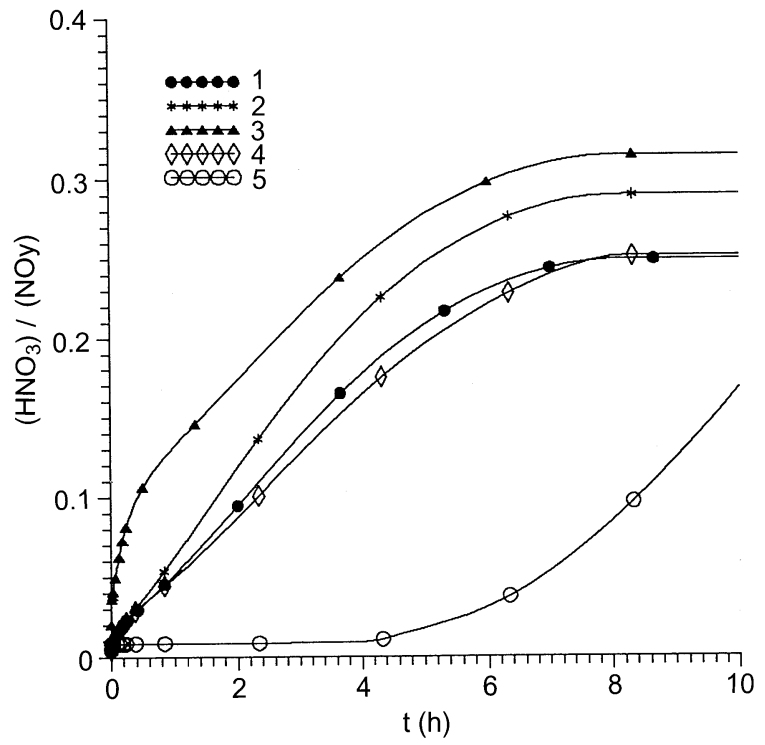

Fig. 8. Same as in Fig. 7 but for $\mathrm{HNO}_{3}$ evolution

sensitivities to some of model parameter variations. The fivefold increase of $\mathrm{OH}$ in exhausts against the basic variant of emissions results in about $10 \%$ reduction of $\mathrm{NO}_{x} / \mathrm{NO}_{y}, 7 \%$ reduction of $\mathrm{NO} / \mathrm{NO}_{y}$ during the entire $10 \mathrm{~h}$ of model plume calculations and in $2-5 \%$ increase of $\mathrm{HNO}_{2} / \mathrm{NO}_{y}$ ratios during the first $2 \mathrm{~h}$ of plume dispersion period. About $7 \%$ of $\mathrm{HNO}_{3} / \mathrm{NO}_{y}$ and $1 \%$ of $\mathrm{HO}_{2} \mathrm{NO}_{2} /$ $\mathrm{NO}_{y}$ increase persist during the entire $10 \mathrm{~h}$ of plume "life". In the case of nighttime emission there is minimal $\mathrm{NO}_{x}$ oxidation and $\mathrm{HNO}_{3}$ formation during the same period.

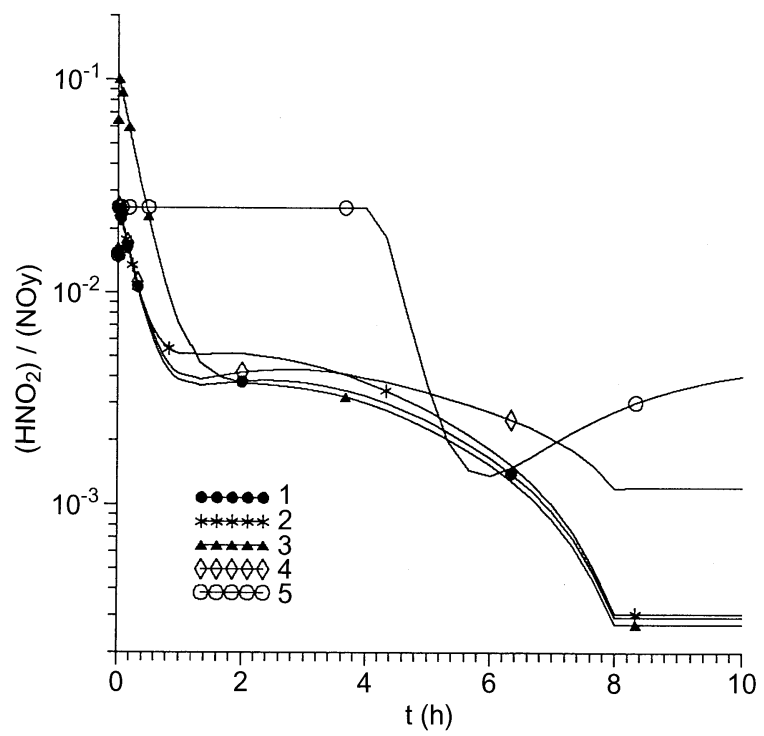

Fig. 9. Same as in Fig. 7 but for $\mathrm{HNO}_{2}$ evolution

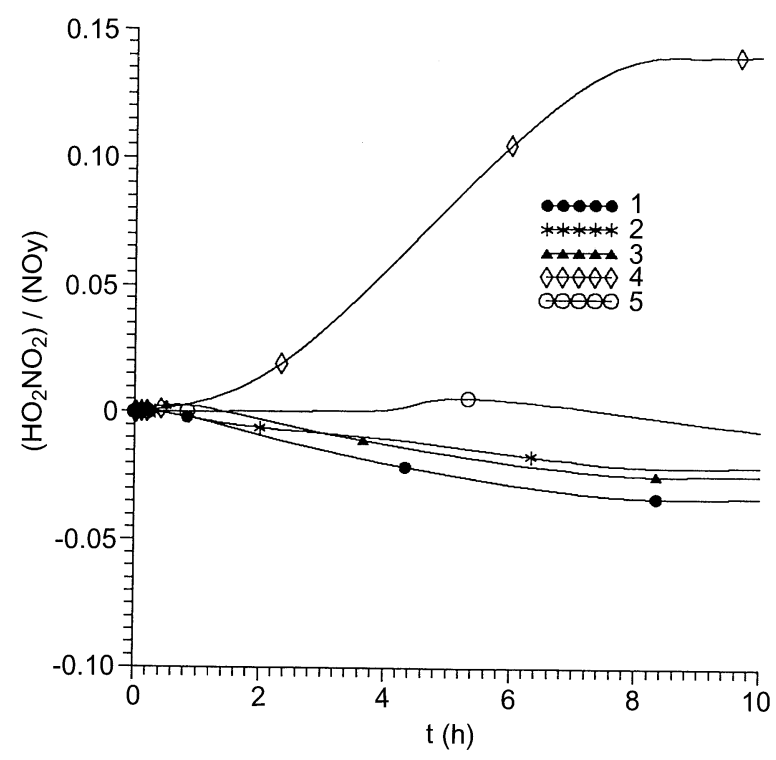

Fig. 10. Same as in Fig. 7 but for $\mathrm{HO}_{2} \mathrm{NO}_{2}$ evolution

Some increases of the ambient air transport into the wide plume in comparison with the basic variant result in $5 \%$ reduction of $\mathrm{NO}_{x} / \mathrm{NO}_{y}$ ratio and in $4 \%$ increase of $\mathrm{HNO}_{3} / \mathrm{NO}_{y}$ at the end of the $10 \mathrm{~h}$ plume period. The maximal $\mathrm{NO}_{x} / \mathrm{NO}_{y}$ reduction to almost $50 \%$ of initially emitted occurs by the end of the same period in the plume in the clean ambient air. This is evidently due to external air inflow into the plume from the clean air background which is low in $\mathrm{NO}_{x}$ and due to enhanced outflow of emitted $\mathrm{NO}_{x}$ from the plume into the low in $\mathrm{NO}_{x}$ external air (see Table 1). The $\mathrm{NO}_{x}$ concentration difference inside and outside of the plume is lower, and $\mathrm{HO}_{x}$ external content is higher in the flight corridor in comparison to clean air conditions, which leads to the differences noted in the plume $\mathrm{NO}_{x}$ oxidation rate. 
Figures 8 and 9 reveal the significant $\mathrm{HNO}_{3} / \mathrm{NO}_{y}$ and $\mathrm{HNO}_{2} / \mathrm{NO}_{y}$ enhancements during the plume "life" for variant with increased $\mathrm{OH}$ emission, when emitted $\mathrm{OH}$ oxidates $\mathrm{NO}$ into $\mathrm{HNO}_{2}$ and $\mathrm{NO}_{2}$ into $\mathrm{HNO}_{3}$ during the first few minutes. Then $\mathrm{HNO}_{2}$ formed disappears in one hour, but $\mathrm{HNO}_{3}$ remains to the end of the plume "life", attaining a maximum of about one third of $\mathrm{NO}_{y}$ content. In the first hours of the plume dispersion during the day $\mathrm{OH}$ and $\mathrm{HO}_{2}$ enter into the plume with the entrained air, and they oxidate $\mathrm{NO}_{x}$ in the plume forming the $\mathrm{HNO}_{2}$, $\mathrm{HNO}_{3}, \mathrm{HO}_{2} \mathrm{NO}_{2}$ content excess there. During the night the opposite happens: the emitted $\mathrm{HO}_{x}$ radicals leave the plume and with low external $\mathrm{HO}_{x}$ produce the low ratio $\mathrm{HNO}_{3} / \mathrm{NO}_{y}$ and, together with the low ratio $\mathrm{HNO}_{2} / \mathrm{NO}_{y}$, conserve these till sunrise. Moderate enhancement of $\mathrm{HNO}_{3} / \mathrm{NO}_{y}$ occurs in the wide plume after about $0.5 \mathrm{~h}$ from emission, and is due to air exchange increase through the plume boundary, bringing more external $\mathrm{OH}$ into the plume for $\mathrm{NO}_{x}$ oxidation. This enhanced air exchange influences the $\mathrm{HNO}_{3}$ formation rate more than the plume and the external $\mathrm{OH}$ level difference in the flight corridor and in the clean air conditions (Table 1), being opposite to the distinct influence of these factors on the $\mathrm{NO}_{x} / \mathrm{NO}_{y}$ time evolution in Fig. 7.

The $\left(\mathrm{HO}_{2} \mathrm{NO}_{2}\right) /\left(\mathrm{NO}_{y}\right)$ time evolution shown in Fig. 10 is significantly different from the $\mathrm{HNO}_{3} / \mathrm{NO}_{y}$ ratio behavior and opposite in the flight corridor (FC) and in the clean air (CA) environment. An intensive formation of $\mathrm{HO}_{2} \mathrm{NO}_{2}$ in the plume in one hour after the emission in the latter case is due to inflow of external air with relatively high $\mathrm{HO}_{2}$ concentration (see Table 1). In the wide plume (WP), with enhanced air exchange through its boundary, the $\mathrm{HO}_{2} \mathrm{NO}_{2} / \mathrm{NO}_{y}$ increase is more pronounced. But in the $\mathrm{FC}$, with lower $\mathrm{HO}_{2}$ and relatively high $\mathrm{OH}$ ambient concentrations, $\mathrm{HO}_{2} \mathrm{NO}_{2} / \mathrm{NO}_{y}$ inside the plume may be slightly deficient relative to its background value during the day, as $\mathrm{HO}_{2} \mathrm{NO}_{2}$ photochemical sink prevails over its source intensities. These $\mathrm{HO}_{2} \mathrm{NO}_{2}$ evolutions do not influence the final $\mathrm{NO}_{y}$ component distributions noticeably in the plume.

\section{Discussion and conclusions}

The results presented of aircraft exhaust plume evolution during the first $10 \mathrm{~h}$ of its "life" by box and Gaussian plume approximations are shown to be in line with known differences in the plume gas concentration distributions, described by these widely used plume models. They also show close proximity in presenting the integral gas content time evolution in the cross section of plume with the same parameters and external conditions. The resulting integral gas content rates of change in the plume cross section are close to each other in both plume models. This important conclusion confirms the wide use of the box plume model in studies of photochemical transformations of emitted atmospheric pollutants.

These simulations support our previous work (Karol et al., 1994) and our conclusions on the substantial influence of ambient air composition, of this air entrainment rate into the plume on the plume gas composition evolution, and on the $\mathrm{NO}_{x}$ oxidation rate into $\mathrm{HNO}_{3}, \mathrm{HO}_{2} \mathrm{NO}_{2}$ in the plume in particular. As was indicated in Karol and Ozolin (1994) the rates of $\mathrm{NO}_{x}$ oxidation and $\mathrm{HNO}_{3}$ formation in the plume are roughly proportional to the $\mathrm{OH}$ (approximately to $\mathrm{H}_{2} \mathrm{O}$ and $\mathrm{O}_{3}$ ) mixing ratio in the clean ambient air with low background $\mathrm{NO}_{x}$ (see Fig. 11). The enhanced $\mathrm{H}_{2} \mathrm{O}$, expected over the North Atlantic FC, favors an increased $\mathrm{NO}_{x}$ oxidation rate in the plume. At the same time the enhanced $\mathrm{NO}_{x}$ background concentrations in the flight corridor reduce the $\mathrm{NO}_{x}$ in $\mathrm{NO}_{y}$ share depletion to the end of the plume "life" as indicated in Fig. 7. The resulting partial compensation of these two processes would obviously depend on the $\mathrm{NO}_{x}$ and $\mathrm{H}_{2} \mathrm{O}$ concentration levels in the FC air, which may obviously vary significantly due to superposition of aircraft exhaust plumes traces there (Schuman and Konopka, 1994). The quantitative estimation of $\mathrm{NO}_{x}$ reduction in the plume to the end of its "life" in the FC would become more complicated with frequent cases of exhaust plume intersections or of plumes imbedding into the expanded plume remnants of previous aircraft cruising along the same trajectory. In the ambient clean air environment the enhanced
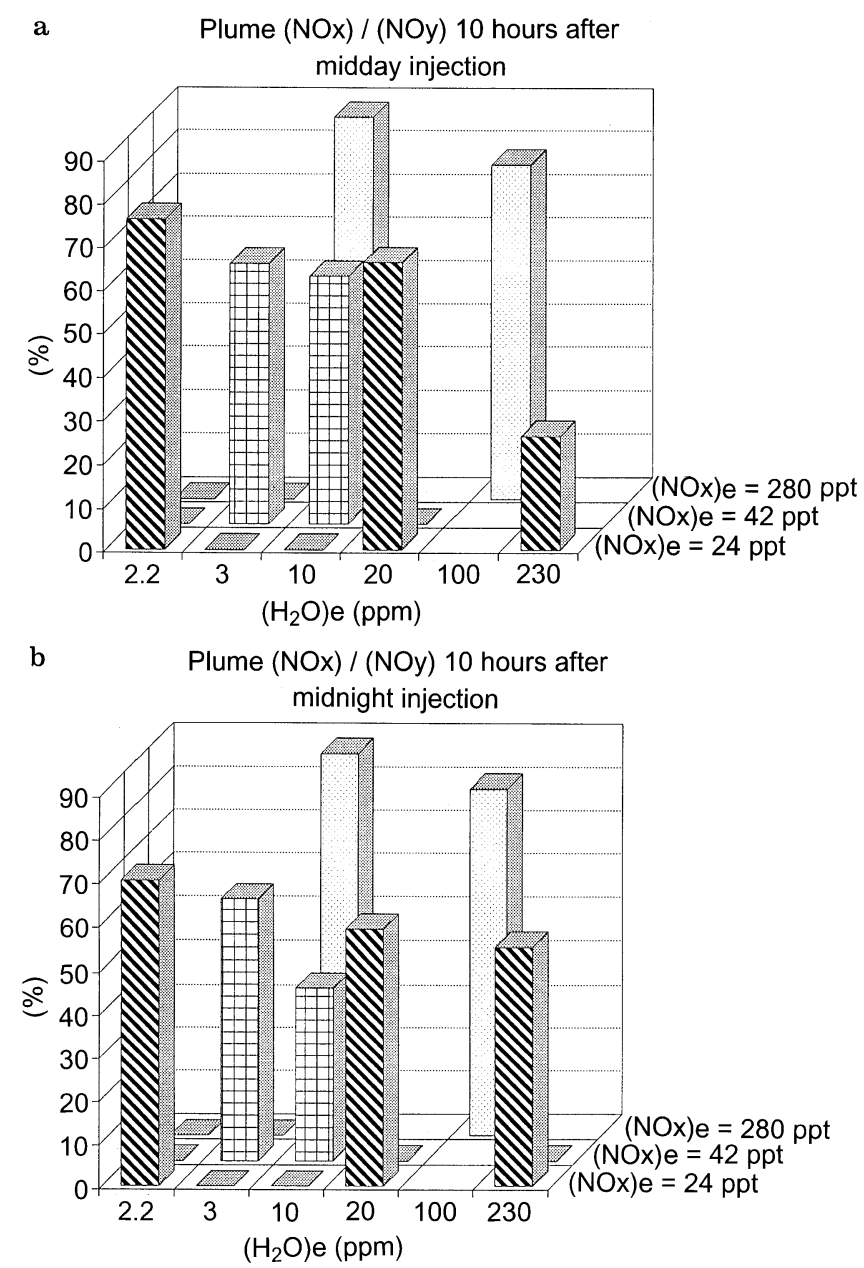

Fig. 11a, b. The box plume $\left(\mathrm{NO}_{x}\right) /\left(\mathrm{NO}_{y}\right)$ ratio $(\%)$ dependence at $10 \mathrm{~h}$ after a the midday and $\mathbf{b}$ midnight injection from the $\left(\mathrm{H}_{2} \mathrm{O}\right)_{e}$ and $\left(\mathrm{NO}_{x}\right)_{e}$ mixing ratios in the external air 
$\Delta\left(\mathrm{NO}_{x}\right) / \Delta\left(\mathrm{NO}_{y}\right)$ drop in the $10 \mathrm{~h}$ period (Fig. 7) is due to the entrainment into the plume of the low in $\mathrm{NO}_{x}$ external air. Because this external air has low $\mathrm{OH}$, but high $\mathrm{HO}_{2}$ (Table 1), it does not influence the $\mathrm{HNO}_{3}$, but enhances the $\mathrm{HO}_{2} \mathrm{NO}_{2}$ formation rate in the plume as may be seen in Figs. 8 and 10. Figure 8 shows, that the enhanced air transport through the "wide" plume boundary in the FC does not influence the $\left(\mathrm{HNO}_{3}\right)$ share in the plume $\left(\mathrm{NO}_{y}\right)$ due to modest external $\mathrm{OH}$ entering into the plume for $\mathrm{NO}_{x}$ oxidation.

Figures 11 and 12 demonstrate the connection of the $\mathrm{NO}_{x}$ and $\mathrm{HNO}_{3}$ shares in $\mathrm{NO}_{y}$ to the end of plume "life" with $\left(\mathrm{NO}_{x}\right)$ and $\left(\mathrm{H}_{2} \mathrm{O}\right)$ mixing ratio in the ambient air, which partly determines the $\mathrm{OH}$ concentration there. For the ambient $\left(\mathrm{H}_{2} \mathrm{O}\right)=$ const., the $\mathrm{NO}_{x} / \mathrm{NO}_{y}$ ratio share increases for background $\left(\mathrm{NO}_{x}\right)$ rise, and for ambient $\left(\mathrm{NO}_{x}\right)=$ const. the same ratio declines for external $\left(\mathrm{H}_{2} \mathrm{O}\right)$ and $(\mathrm{OH})$ enhancement, reflecting the already found compensating influence of the background air composition on the $\mathrm{NO}_{x}$ oxidation rate in the plume. A connection for the $\mathrm{HNO}_{3} / \mathrm{NO}_{y}$ ratio with external $\left(\mathrm{NO}_{x}\right)_{e}$ and $\left(\mathrm{H}_{2} \mathrm{O}\right)_{e}$ over the $10 \mathrm{~h}$ plume life is presented at Fig. 12. The almost linear increase of this ratio for ambient $\left(\mathrm{H}_{2} \mathrm{O}\right)$ and $(\mathrm{OH})$ rise is understandable. The sharp decline of the $\mathrm{HNO}_{3}$

a

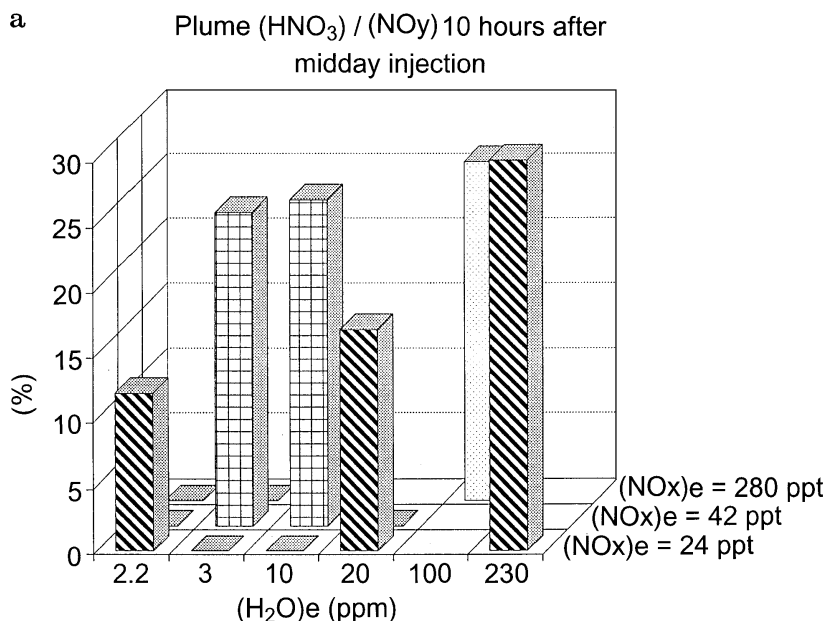

b Plume $\left(\mathrm{HNO}_{3}\right) /(\mathrm{NOy}) 10$ hours after midnight injection

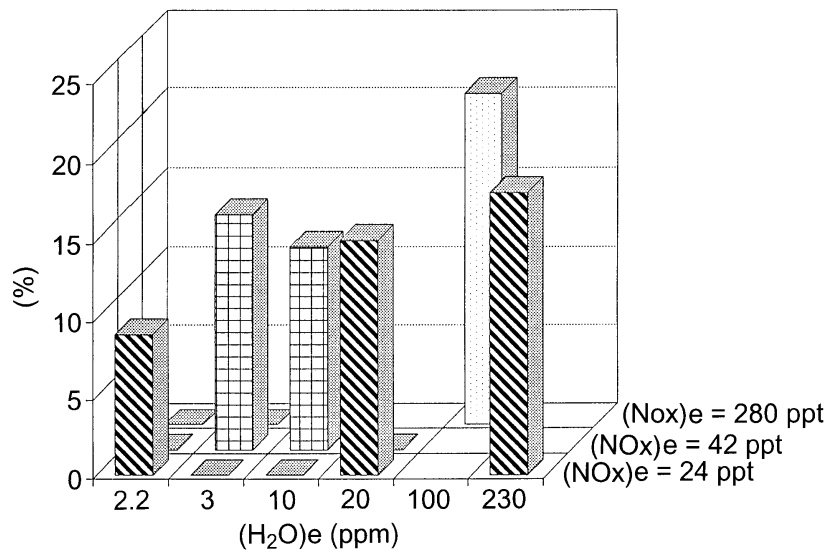

Fig. 12a, b. Same as in Fig. 11 but for $\left(\mathrm{HNO}_{3}\right) /\left(\mathrm{NO}_{y}\right)$ share in $\mathrm{NO}_{y}$ in the plume for flight corridor $\mathrm{NO}_{x}$ levels in the ambient air and for clean air $\left(\mathrm{H}_{2} \mathrm{O}\right)$ and $\mathrm{HO}_{x}$ concentrations is the evident result of the very low $\mathrm{NO}_{x}$ oxidation rate in the plume in these conditions (only about 10\% of emitted $\mathrm{NO}_{x}$ is oxidized, see Fig. 11).

All these results suggest the feasibility of introducing into the assessment of aircraft emission atmospheric effects the concept of the Effective Emission Index (EEI) as a generalization and development of the well-known Emission Index (EI), which indicates the $\mathrm{NO}_{x}$ emitted from engine in terms of grams per kilogram of fuel burned (Schuman, 1994; Schulte and Schlanger, 1994; WMO, 1995). Only EEI and not EI has to be used in evolution of $\mathrm{NO}_{x}$ atmospheric sources from the aircraft exhausts in global modeling of their atmospheric effects.

In addition to the model calculations and laboratory testing, the actual EI is determined now also by $\mathrm{NO}_{x}$ measurements in the aircraft plume crossings by research aircraft (Schulte and Schlager, 1994; Fahey et al., 1995). The EEI evaluation and its sensitivity studies may be carried out not only by extensive modeling, but also by actual aircraft measurements of $\mathrm{NO}_{y}$ component contents in exhaust plumes in various environments and flight conditions. EEI evaluation and research is a large complicated task and this study is only the first step in this direction.

Acknowledgements. This study is supported by the Russian Basic Research Foundation, grant 93-05-8500 and International Science Foundation, grants R-15000 and R-15300.

Authors and topical Editor L. Eymard thanks two referees for their help in evaluating and editing this paper.

\section{References}

Arnold, F., J. Schneider, M. Klemm, J. Scheid, T. Stilp, H. Schlager, P. Schulte, and M. Reinhardt, Mass spectrometer measurements of $\mathrm{SO}_{2}$ and reactive nitrogen gases in exhaust plumes of commercial jet airliners at cruise altitude, in Impact of emissions from aircraft and spacecraft upon the atmosphere, Eds. U. Schumann, D. Würzel, DLR Mitteillung 94-06, Köln, 322-328, 1994.

Danilin, M. Yu, B. C. Kruger, and A. Ebel, Short-term atmospheric effects of high altitude aircraft emissions, Ann. Geophysicae, 10, 904-911, 1992.

Fahey, D. W., E. R. Kent, E. L. Woodbridge, R. S. Gao, K. A. Boering, B. C. Daube, S. C. Wofsy, R. P. Lohmann, E. J. Hintsa, A. E. Dessler, C. R. Webster, R. D. May, C. A. Brock, J. C. Wilson, R. C. Miake-Lye, R. C. Brown, J. M. Rodriguez, M. Loewenstein, M. H. Profitt, R. M. Stimpfle, S. Bowen, and K. R. Chan, In situ observation in aircraft exhaust plumes in the lower stratosphere at mid-latitudes, J. Geophys. Res., 100, 3065-3074, 1995.

Hoinka, K. P., M. E. Reinhardt, and W. Metz, North Atlantic air traffic within the lower stratosphere: cruising times and corresponding emissions, J. Geophys. Res., 98, 23113-23131, 1993.

Karol, I. L., and Y. E. Ozolin, Small- and medium scale effects of high flying aircraft exhausts on the atmospheric composition, Ann. Geophysicae, 12, 979-985, 1994.

Karol, I. L., Y. E. Ozolin, and E. V. Rozanov, Effect of space rocket launches on ozone Ann. Geophysicae, 10, 810-814, 1992.

Karol, I. L., Y. E. Ozolin, and E. V. Rozanov, Modeling mesoscale gas-phase and heterogeneous photochemistry in the aircraft engine exhaust plume interacting with the ambient atmosphere, in Impact of emissions from aircraft and spacecraft upon the atmosphere", Eds. U. Schumann, D. Würzel, DLR Mitteillung 94-06, Köln, 342-347, 1994. 
Kärcher, B., Transport of exhaust products in the near trail of a jet engine under atmospheric conditions, J. Geophys. Res., 99, 14509-14517, 1994.

Ko, M. K. W., and A. R. Douglass, Update of model simulations for the effects of stratospheric aircraft, in The atmospheric effects of stratospheric aircraft: a third program report, NASA Ref. Publ. 1313, NASA, 209-243, 1993.

Miake-Lye, R. C., M. Martinez-Sanchez, R. C. Brow, and C. E. Kobb, Plume and wake dynamics, mixing and chemistry behind an HSCT aircraft, J. Aircr., 30, 467-479, 1993.

Pleÿel, K., J. Moldanova, and Y. Anderson-Sköld, Chemical modelling of an aeroplane exhaust plume in the free troposphere, in Impact of emissions from aircraft and spacecraft upon the atmosphere, Eds. U. Schumann, D. Würzel, DLR Mitteillung 94-06, Köln, 280-285, 1994.

Schlager, H., P. Schulte, H. Volkert, R. Busen, and U. Schumann, Observations of enhanced nitric oxide abundances within the North Atlantic flight corridor, in Impact of emissions from aircraft and spacecraft upon the atmosphere, Eds. U. Schumann, D. Würzel, DLR Mitteillung 94-06, Köln, 336-341, 1994.

Schulte, P., and H. Schlager, Inferred $\mathrm{NO}_{x}$ emission indices of jet engines at cruise altitudes from in situ $\mathrm{NO}$ and $\mathrm{CO}$ measurements within aircraft plumes, in Impact of emissions from aircraft and spacecraft upon the atmosphere", Eds. U. Schumann, D. Würzel, DLR Mitteillung 94-06, Köln, 113-118, 1994.
Schumann, U., On the effect of emissions from the aircraft engine on the state of the atmosphere, Ann. Geophysicae, 12, 365-384, 1994.

Schumann, U., and P. Konopka, A simple estimations of the concentration field in a flight corridor, in Impact of emissions from aircraft and spacecraft upon the atmosphere, Eds. U. Schumann, D. Würzel, DLR Mitteillung 94-06, Köln, 354-359, 1994.

Schumann, U., and D. Würzel, Eds., Impact of emissions from aircraft and spacecraft upon the atmosphere, DLR Mitteillung 94-06, Köln, 496 p, 1994.

Schumann, U., P. Konopka, R. Baumann, R. Busen, T. Gerz, H. Schlanger, P. Schulte, and H. Volkert, Estimate of diffusion parameters of aircraft exhaust plumes near the tropopause from nitric oxide and turbulence measurements, J. Geophys. Res., 100 (D7), 14147-14162, 1995.

Veenstra, D., and J. Beck, An aircraft exhaust plume model, in Impact of emissions from aircraft and spacecraft upon the atmosphere, Eds. U. Schumann, D. Würzel, DLR Mitteillung 94-06, Köln, 286-291, 1994.

World Meteorological Organization, Scientific assessment of ozone depletion: 1994, WMO Global Ozone Res. and Monitoring Project-Rep. 37, Ch. 11, 1995.

Zheng, J., A. J. Weinheimer, B. A. Ridley, S. C. Liu, S. W. Sachse, B. E. Anderson, and J. E. Collins, An analysis of aircraft exhaust plumes from accidental encounters, Geophys. Res. Lett., 21, 2579-2582, 1994. 